\title{
KORELASI REGISTRASI TENAGA KESEHATAN TERHADAP KOMPENTENSI TENAGA KESEHATAN DALAM PELAYANAN KESEHATAN MASYARAKAT
}

\author{
Sri Retno Widyorini*
}

\begin{abstract}
Health as one of the elements of general welfare must be realized through various health efforts in the context of comprehensive and integrated health development supported by a national health system. Health workers who will carry out health services to the community must have a STR (Surat Tanda Registrasi/Registration Certificate) issued by the government as the person in charge of public health services. Physicians as one of the health workers are responsible for providing health services in accordance with applicable legislation namely Law Medical Practice and Doctor's Code of Ethics. Doctors who practice health services to the community at the hospital are bound by the Doctor's Code of Ethics and are also bound by the Hospital By Laws as an internal provision of the hospital.
\end{abstract}

Keywords :Health, Hospital By Laws, Practice Health Services,

\section{PENDAHULUAN}

Cita-cita Bangsa Indonesia sebagaimana tercantum di dalam pembukaan Undang-undang Dasar Negara republic Indonesia Tahun 1945 adalah melindungi segenap bangsa Indonesia dan seluruh tumpah darah Indonesia dan untuk memajukan kesejahteraan umum, mencerdaskan kehidupan bangsa dan ikut melaksanakan ketertiban dunia yang berdasarkan kemerdekaan, perdamaian abadi, dan keadilan sosial. Kesehatan sebagai salah satu unsure kesejahteraan umum harus diwujudkan melalui berbagai upaya kesehatan dalam rangka pembangunan kesehatan secara menyeluruh dan terpadu yang didukung oleh suatu sistem kesehatan nasional.

Pasal 28 ayat (1) UUDNRI Tahun 1945 menekankan bahwa setiap orang

* Sri Retno Widyorini adalah Pengajar di Fakultas Hukum UNTAG Semarang, Bidang Kajian Hukum Perdata, Sekarang sedang menempuh studi Program Doktor Ilmu Hukum UNTAG Semarang dapat di hubungi melalui email : sriretnowidyorini@gmail.com berhak hidup sejahtera lahir dan batin, bertempat tinggal dan mendapatkan lingkungan hidup yang baik dan sehat serta berhak memperoleh pelayanan kesehatan. Dari apa yang tersurat dalam bunyi Pasal 28 ayat 1 UUDNRI Tahun 1945 ini memberikan kejelasan bahwa kesehatan adalah merupakan kebutuhan dasar manusia dan merupakan hak dari setiap warga Negara. Dan hukum merupakan sarana untuk mewujudkan hak-hak manusia dalam memenuhi kebutuhannya, sehingga hakikat dari hukum adalah perlindungan kepentingan manusia termasuk di dalamnya adalah mewujudkan kesehatan. Untuk mewujudkan kesehatan dari masyarakat diperlukan fasilitas pelayanan kesehatan, tenaga kesehatan dan juga sarana prasarana yang mendukung .

Pasal 1 ayat (1) dari Undangundang Nomor 36 Tahun 2009 tentang Kesehatan mengatakan, bahwa : "Kesehatan adalah keadaan sehat, baik secara fisik, mental,spiritual maupun sosial yang memungkinkan setiap orang untuk hidup produktif secara sosial dan 
ekonomis".Sementara itu pada Pasal 1 ayat (6) mengatakan bahwa ; Tenaga kesehatan adalah setiap orang yang mengabdikan diri dalam bidang kesehatan serta memiliki pengetahuan dan/atau ketrampilan melalui pendidikan di bidang kesehatan yang untuk jenis tertentu memerlukan kewenangan untuk melakukan upaya kesehatan.uapaya kesehatan tersebut diberikan dalam bentuk pelayanan kesehatan, yang bisa dilakukan di tempat fasilitas pelayanan kesehatan. Sebelum seorang tenaga kesehatan melakukan pelayanan kesehatan kepada masyarakat sesuai dengan standar profesinya, maka diwajibkan untuk melakukan registrasi kesehatan sebagai mana yang di atur di dalam Permenkes Nomor 46 Tahun 2013 tentang Registrasi Tenaga Kesehatan. Tenaga kesehatan yang sudah melakukan registrasi akan mendapat kan Surat Tanda Registrasi (STR) yang dikeluarkan oleh pemerintah. Dengan STR tersebut maka tenaga kesehatan dianggap layak dan mampu untuk melakukan pelayanan kesehatan kepada masyarakat.

\section{Pembatasan Masalah}

Pembahasan materi yang berkaitan dengan tenaga kesehatan yang melakukan pelayanan kesehatan kepada masyarakat di tempat fasilitas kesehatan sangatlah luas dan kompleks. oleh karena itu agar pembahasan lebih terfokus pada permasalahan yang diajukan, maka penulis membatasi pada tenaga kesehatan dan fasilitas pelayanan kesehatan. Tenaga kesehatan yang dimaksud dalam bahasan tulisan ini adalah tenaga kesehatan medis yaitu Dokter, sementara fasilitas pelayanan kesehatan yang dimaksud dalam bahasan ini adalah Rumah Sakit.

\section{Perumusan Masalah}

1. Bagaimanakah hubungan hukum antara registrasi tenaga kesehatan dan pelayanan kesehatan masyarakat?
2. Bagaimanakah tanggung jawab Dokter sebagai tenaga kesehatan dalam melakukan pelayanan keehatan kepada masyarakat?

3. Apakah kendala yang dihadapi oleh dokter sebagai tenaga kesehatan dalam melakukan pelayanan kesehatan di rumah sakit dan solusi untuk mengatasinya?

\section{Pembahasan Masalah}

1. Hubungan hukum antara registrasi tenaga kesehatan dengan peningkatan pelayanan kesehatan masyarakat.

Sebagaimana dikatakan oleh Cecep Tri Wibowo bahwa hakikat dari hukum adalah perlindungan kepentingan manusia yang salah satunya adalah mewujudkan kesehatan. ${ }^{1}$

Setiap warga negara berhak untuk mendapatkan pelayanan kesehatan yang baik yang diberikan oleh tenaga kesehatan sesuai dengan standar profesinya. Salah satu persyaratan bagi tenaga kesehatan untuk dapat menjalankan pekerjaannya dalam memberikan pelayanan kesehatan kepada masyarakat sesuai dengan disiplin ilmunya adalah bahwa tenaga kesehatan tersebut harus mempunyai Surat Tanda Registrasi (STR). Surat Tanda Registrasi adalah persyaratan normatif yang berkaitan dengan kualifikasi dari tenaga kesehatan yang bersangkutan .

Prosedur untuk mendapatkan Surat Tanda Registrasi adalah sebagai berikut:

a. Tenaga kesehatan harus mengikuti uji kompetensi yang dilakukan oleh Perguruan Tinggi Bidang kesehatan yang terakreditasi dari badan yang berwenang bersamaan dengan pelaksanaan ujian akhir.

b. Bagi tenaga kesehatan yang telah lulus ujian progam pendidikan dan uji

1 Cecep Tri Wibowo, 2014, Etika Hukum Kesehatan, Nusa Medika, Yogyakarta, Hal.13. 
kompetensi akan mendapat ijazah dan sertifikat kompetensi .Ijazah dikeluarkan oleh perguruan tinggi bidang kesehatan sesuai dengan peraturan perundang-undangan. Sertifikat kompetensi dikeluarkan oleh MTKI (Majelis Tenaga Kesehatan Indonesia).MTKI adalah lembaga yang berfungsi untuk menjamin mutu tenaga kesehatan yang memberikan pelayan kesehatan. Masa berlakunya sertifikat kompetensi adalah selama 5(lima) tahun dan dapat diperpanjang setiap 5 (lima) tahun.

c. Sertifikat kompetensi akan dipakai oleh tenaga kesehatan sebagai salah satu persyaratan untuk melakukan registrai tenaga kesehatan, dan bagi tenaga kesehatan yang telah melakukan registrasi dan memenuhi standar sesuai kualifikasinya akan diberikan Surat Tanda Registrasi (STR) oleh pemerintah cq instansi yang berwenang. Surat Tanda Registrasi (STR) adalah bukti tertulis yang diberikan oleh pemerintah kepada tenaga kesehatan yang telah memiliki sertifikat kompetensi. Dimilikinya STR bagi seorang tenaga kesehatan membawa pengertian bahwa ybs bisa melakukan pekerjaan sesuai dengan kualifikasi profesinya untuk memberi kan pelayanan kesehatan kepada masyarakat.

Dari penjelasan tersebut di atas dapat ditarik pengertian bahwa hubungan hukum antara registrasi tenaga kesehatan dengan pelayanan kesehatan kepada masyarakat adalah, bahwa hanya tenaga kesehatan yang telah mempunyai Surat Tanda Registrasilah yang oleh peraturan perundangan yang berlaku diijinkan untuk memberikan pelayanan kesehatan kepada masyarakat. Hal ini disebabkan karena tenaga kesehatan yang telah memiliki STR (Surat Tanda Registrasi) berarti tenaga kesehatan tersebut telah melakukan registrasi, dan registrasi hanya boleh dilakukan oleh tenaga kesehatan yang telah memenuhi persyaratan yaitu memiliki ijazah atau tanda kelulusan dari perguruan tinggi di bidang kesehatan yang terakreditasi sesuai dengan standard kualifikasi profesinya dan juga sudah memiliki sertifikat kompetensi yang dikeluarkan oleh Majelis Tenaga Kesehatan Indonesia sebagai lembaga yang menjamin mutu dari tenaga kesehatan ybs untuk memberikan pelayanan kesehatan kepada masyarakat sesuai dengan kualifikasi profesinya masing-masing. Oleh karena itu dapat dikatakan bahwa tenaga kesehatan yang tidak melakukan regisitrasi kesehatan maka tenaga kesehatan tersebut tidak boleh melakukan pelayanan kesehatan kepada masyarakat karena tidak memiliki sertifikat kompetensi yang disebut dengan Surat Tanda Registrasi yang berfungsi sebagai pengakuan atas kualifikasi profesinya yang dikeluarkan oleh pemerintah sebagai pemangku kepentingan yang bertanggung jawab terhadap pelayanan kesehatan masyarakat sebagai warga negara untuk meningkatkan derajat kesehatannya sesuai dengan tujuan kemerdekaan yang tertuang di dalam Pembukaan UUDNRI Tahun 1945 pada alinea keempat.

Tenaga kesehatan yang tidak memiliki STR (Surat Tanda Registrasi) sebagai bukti telah melakukan registrasi kesehatan tetapi melakukan pelayanan kesehatan kepada masyarakat dapat dikenai sanksi baik secara perdata, pidana maupun sanksi administrasi.

\section{Tanggung jawab Dokter sebagai tenaga kesehatan dalam melakukan pelayanan kesehatan kepada masyarakat.}

Kesehatan merupakan kebutuhan dan hak setiap warga negara dan negara wajib untuk menjamin pemenuhan hak atas kesehatan dari masyarakatnya. Kesehatan terkait erat dengan kualitas sumber daya manusia pada suatu negara. Sehat adalah 
keadaan yang optimal, baik fisik, mental maupun sosial dan tidak hanya terbatas pada keadaan bebas dari penyakit atau kelemahan saja. ${ }^{2}$ Setiap orang berhak atas kesehatan (Pasal 4 UU No.36 Tahun 2009 tentang kesehatan ) Pasal 9 Ayat 3 Undangundang Nomor 39 Tahun 1999 Tentang Hak Asasi manusia juga menyebutkan bahwa setiap orang berhak atas lingkungan hidup yang baik dan sehat. Begitu juga Pasal $28 \mathrm{H}$ ayat 1 dari UUDNRI Tahun 1945 juga mengatur bahwa setiap orang berhak hidup sejahtera lahir dan batin, bertempat tinggal dan mendapatkan lingkungan hidup yang baik dan sehat dan berhak memperoleh pelayanan kesehatan.Dari bunyi pasal yang ada di 3 (tiga ) peraturan perundangan tersebut jelas bahwa kesehatan merupakan hak asasi manusia yang harus dilindungi oleh negara.

Peningkatan mutu kesehatan tidak bisa dilepaskan dari peningkatan kualitas pelayanan kesehatan yang dilakukan oleh tenaga kesehatan. Sebagaimana diketahui bahwa tenaga kesehatan adalah setiap orang yang mengabdikan diri dalam bidang kesehatan serta memiliki pengetahuan atau ketrampilan melalui pendidikan di bidang kesehatan yang untuk jenis tertentu memerlukan kewenangan untuk melakukan upaya kesehatan. Pada prinsipnya ada dua kategori pelayanan kesehatan : ${ }^{3}$

a. Kategori yang berorientasi pada public (masyarakat)

b. Kategori yang berorientasi pada perorangan (pribadi).

Menurut Undang-undang Nomor 25 Tahun 2009 tentang Pelayanan Publik, pelayanan publik adalah :

" kegiatan atau rangkaian kegiatan dalam rangka pemenuhan kebutuhan dasar sesuai dengan hak-hak sipil setiap warga negara dan penduduk atas suatu barang, jasa dan

2 A.A. Gde Maninjaya, 2004, Manajemen Kesehatan Edisi 2, EGC, Jakarta, Hal. 45.

3 Soekidjo Notoatmojo,2007, Promosi Kesehatan dan Ilmu Perilaku, Rineka Cipta, Jakarta, hal.207 atau pelayanan administrasi yang diselenggarakan oleh penyelenggara pelayanan publik".

Penyelenggara wajib menyusun dan menetapkan standar pelayanan sesuai dengan sifat, jenis dan karakteristik layanan yang diselenggarakan dengan memperhati kan lingkungan dan masukan masyarakat dan pihak terkait. Penyusunan dan penetapan standar pelayanan sebagaimana yang dimaksud termasuk di dalamnya adalah standar pelayanan kesehatan kepada masyarakat, termasuk di dalamnya adalah standar tenaga kesehatan yang akan melakukan playanan kesehatan kepada masyarakat.

Dokter adalah salah satu tenaga kesehatan medis, yang dalam menjalankan profesinya berdasarkan ketentuan peratur an perundangan yang berlaku. Pasal 1 ayat (9) Undang-undang Nomor 20 tahun 2013 tentang Pendidikan Kedokteran mengata kan bahwa Dokter adalah dokter, dokter layanan primer, dokter spesialis-sub spesialis lulusan pendidikan dokter, baik di dalam maupun di luar negeri yang diakui oleh pemerintah. Pasal 28 Ayat (1) Undangundang Nomor 29 Tahun 2004 tentang praktik kedokteran menyebutkan bahwa setiap dokter atau dokter gigi yang berpraktik wajib untuk mengikuti pendidik an atau pelatihan kedokteran atau kedokteran gigi berkelanjutan yang diselenggarakan oleh organisasi profesi atau lembaga lain yang diakreditasi oleh organisasi profesi dalam rangka penyerap an perkembangan ilmu pengetahuan dan teknologi kedokteran atau kedokteran gigi.

Dalam melakukan pelayanan kesehatan kepada pasien (masyarakat pengguna jasa kesehatan) akan terjadi hubungan hukum yang disebut dengan Transaksi Terapeutik. Secara yuridis perjanjian terapeutik diartikan sebagai hubungan hukum antara tenaga kesehatan dengan pasien dalam pelayanan medis secara profesional didasarkan pada kompetensi yang sesuai dengan keahlian 
dan ketrampilan tertentu di bidang kesehatan. Menurut Koeswadji dalam bukunya Cecep Wibowo mengatakan bahwa: Transaksi terapeutik adalah perjanjian (verbintenis) untuk mencari atau menentukan terapi yang paling tepat bagi pasien oleh dokter dan tenaga kesehatan. ${ }^{4}$ Sementara itu Veronica Komalawati dalam buku yang sama mengatakan bahwa, transaksi terapeutik adalah hubungan hukum tenaga kesehatan dan pasien dalam pelayanan medis secara profesional didasarkan pada kompetensi yang sesuai dengan keahlian dan ketrampilan tertentu di bidang kedokteran. ${ }^{5}$ Kepmenkes RI No. 434 / MEN.KES / X / 1983 tentang berlakunya KODEKI (Kode Etik Kedokteran Indonesia) bagi para dokter di Indonesia dalam mukadimahnya mengatakan bahwa yang dimaksud dengan transaksi terapeutik adalah hubungan antara dokter dan penderita yang dilakukan dalam suasana saling percaya (konfidensial), serta senantiasa diliputi oleh segala emosi, harapan dan kekahawatiran makluk insani, sehingga dapat ditarik pengertian bahwa transaksi terapeutik adalah hubungan antara dua subyek hukum yang saling mengikatkan diri didasarkan sikap saling percaya. Perjanjian terapeutik yang juga dikenal dengan kontrak terapeutik yang merupakan upaya maksimal dokter dan/ atau tenaga kesehatan untuk menyembuh kan pasien (inspaningsverbintenis). Dalam kontrak terapeutik ini dokter dan/atau tenaga kesehatan hanya berusaha untuk menyembuhkan pasien dan upaya yang dilakukan belum tentu berhasil. Transaksi terapeutik ini akan berakhir karena beberapa hal, diantaranya adalah karena:

a. Sembuhnya pasien

b. Dokter (tenaga kesehatan) mengudur kan diri

c. Pengakhiran oleh pasien

d. Meninggalnya pasien

e. Karena persetujuan kedua belah pihak

4 Cecep Wibowo, Op. Cit, Hal. 62.

5 Ibid. f. Sudah selesainya kewajiban dokter (tenaga kesehatan) seperti yang ditentukan dalam kontrak

g. Dalam keadaan gawat darurat apabila dokter pilihan pasien sudah datang atau penghentian keadaan gawat darurat tsb.

Tanggung jawab dokter sebagai tenaga kesehatan secara hukum tertuang di dalam perjanjian terapeutik yang terjadi antara dokter dan pasien, terjadinya perjanjian ini didasarkan pada suasana saling percaya, adanya harapan untuk kesembuhan pasien juga kekhawatiran jika tindakan yang dilakukan oleh dokter dalam melakukan pelayanan kesehatan tersebut tidak berhasil sebagaimana yang diharap kan, namun dokter akan berusaha secara maksimal sesuai dengan kompetensi profesinya untuk melakukan pelayanan kesehatan secara professional.

Persetujuan pasien terhadap tindakan medis yang akan dilakukan dokter kepada pasien disebut dengan informed consent. Persetujuan ini juga boleh diberikan oleh keluarga apabila dalam keadaan pasien tidak mungkin untuk memberikan persetujuannya.Secara yurisdis informed consent ini menunjukkan adanya peraturan hukum yang menentukan kewajiban para tenaga medis (dokter) dalam interaksi dengan pasien. Di samping itu juga memberikan sanksi ( dalam keadaan tertentu ) apabila terjadi penyimpangan terhadap apa yang sudah ditentukan. Secara hakiki informed consent juga mengandung nilai-nilai luhur tentang hakikat kemanusiaan yang harus menghormati hak azasi manusia, dalam hal ini adalah hak azasi dari pasien untuk menentukan nasibnya sendiri, yaitu dengan menyetujui atau menolak atas tindakan medis yang akan dilakukan oleh dokter sesuai dengan kompetensi profesinya untuk tujuan penyembuhan penyakit dari si pasien tersebut.

Dari uraian tersebut di atas dapat disimpulkan bahwa dokter sebagai tenaga kesehatan di bidang medis bertanggung 
jawab untuk melakukan pelayanan kesehatan kepada pasien ( masyarakat pengguna jasa pelayanan kesehatan ) untuk melakukan tindakan medis demi untuk kesembuhan pasien. Namun demikian sebelum tindakan tersebut dilakukan tenaga kesehatan dalam hal ini adalah dokter berkewajiban untuk memberikan penjelasan kepada paien atau keluarganya untuk dilakukannya tindakan medis. Kesepakatan antara dokter sebagai tenaga kesehatan dengan pasien sebagai penerima pelayanan kesehatan disebut dengan perjanjian atau kontrak terapeutik. Selajutnya persetujuan pasien atau keluarganya (dalam keadaan tertentu ) atas tindakan yang akan dilakukan oleh dokter kepada pasien disebut dengan informed consent.

3. Kendala yang dihadapi dokter sebagai tenaga kesehatan dalam memberikan pelayan kesehatan di rumah sakit dan solusi penyelesian nya.

Rumah sakit adalah salah satu fasilitas kesehatan yang digunakan oleh dokter sebagai tenaga kesehatan dalam memberikan pelayanan kesehatan kepada masyarakat. Menurut ketentuan Undangundang Nomor 44 Tahun 2009 tentang Rumah sakit pada Pasal 1 Ayat (1), Rumah sakit adalah institusi pelayanan keshatan yang menyelenggarakan pelayanan kesehatan perorangan secara paripurna yang menyediakan pelayanan rawat inap, rawat jalan dan gawat darurat. Gawat darurat adalah keadaan klinis pasien yang membutuhkan tindakan media segera guna penyelmatan nyawa dan pencegahan kecacatan lebih lanjut. Pelayanan kesehatn paripurna adalah pelayanan kesehatan yang meliputi promotif, preventif, kuratif dan rehabilitatif.Pasien adalah setiap orang yang melakukan konsultasi masalah kesehatan untuk memperoleh pelayanan kesehatan yang diperlukan, baik secara langsung maupun tidak langsung di rumah sakit.

Tujuan penyelenggaraan rumah sakit sebagai salah satu fasilitas kesehatan sebagaimana yang tertuang didalam Pasal 3 UU Nomor 44 Tahun 2009 tentang Rumah Sakit adalah:

a. Mempermudah akses masyarakat untuk mendapatkan pelayanan kesehatan

b. Memberikan perlindungan terhadap keselamatan pasien, masyarakat, lingkungan rumah sakit dan sumber daya manusia di rumah skit,

c. Meningkatkan mutu dan mempertahan kan standar pelayanan rumah sakit

d. Memberikan kepastian hukum kepada pasien, masyarakat, sumber daya rumah sakit dan rumah sakit.

Berdasarkan jenis pelayanan yang diberikan, rumah sakit dikategorikan dalam rumah sakit umum dan rumah sakit khusus. Rumah sakit umum adalah rumah sakit yang memberikan pelayanan pada semua bidang dan jenis penyakit, sedangkan rumah sakit khusus adalah rumah sakit yang memberikan pelayanan utama pada satu bidang atau satu jenis penyakit tertentu berdasarkan disiplin ilmu, golongan umur, organ, jenis penyakit atau kekhususan lainnya. Berdasarkan pengelolaannya rumah sakit dapat dibagi menjadi rumah sakit publik dan rumah sakit privat. Rumah sakit publik adalah rumah sakit yang dikelola oleh pemerintah, pemerintah daerah dan badan hukum yang bersifat nirlaba. Rumah sakit publik yang dikelola oleh pemerintah dan pemerintah daerah diselenggarakan berdasarkan badan layanan umum atau badan layanan umum daerah sesuai dengan ketentuan peraturan perundang-undangan. Rumah sakit publik yang dikelola oleh pemerintah dan pemerintah daerah tidak dapat dialihkan menjadi rumah sakit privat.Sedangkan rumah sakit privat dikelola oleh badan hukum dengan tujuan profit yang berbentuk Perseroan Terbatas atau Persero. 
Dalam operasionalnya sebagai fasilitas pelayanan kesehatan masingmasing rumah sakit mempunyai peraturan internal yang harus ditaati oleh seluruh sumber daya yang ada di rumah sakit tersebut, termasuk di dalamnya adalah dokter sebagai tenaga kesehatan yang memberikan pelayanan kesehatan di rumah sakit. Peraturan internal untuk mengatur seluruh management yang ada di rumah sakit disebut dengan Hospital By laws.

Dokter yang memberikan pelayanan kesehatan di rumah sakit tidak hanya terikat pada Kode Etik Dokter akan tetapi juga harus patuh pada hospital By Laws sebagai ketentuan internal dari rumah sakit yang bersangkutan. Hospital By Laws akan dituangkan di dalam SOP (Standar Operasional Prosedur) dari setiap tindakan medis maupun non medis yang harus dilakukan oleh dokter sebagai tenaga kesehatan di bidang medis maupun oleh para medis yang membantu tugas dokter dalam penanganan pelayanan kesehatan, maupun seluruh tindakan lain yang berkaitan dengan pelayanan kesehatan di rumah sakit yang dilakukan oleh sumber daya di rumah sakit yang bersangkutan. Kondisi yang demikian kadang- kadang akan menjadi kendala dari dokter yang bersangkutan di dalam melakukan pelayanan kesehatan kepada masyarakat.

Solusi untuk mengatasi perbedaan antara dokter sebagai tenaga kesehatan yang wajib untuk memberikan pelayanan kesehatan kepada pasien yang datang berobat ke rumah sakit dengan peraturan internal rumah sakit sebagi fasilitas tempat pelayanan kesehatan adalah dengan cara saling memahami dan menyatukan visi bahwa tujuan utama dilakukannya pelayanan kesehatan adalah untuk menolong pasien terlepas dari penderitaan karena penyakit yang dideritanya. Sehingga akan dapat dicapai peningkatan derajat kesehatan masyarakat yang dilkukkan dengan cara memberikan pelayanan kesehatan yang maksimal.

\section{Kesimpulan}

Tenaga kesehatan yang akan melakukan pelayanan kesehatan kepada masyarakat harus mempunyai STR ( Surat Tanda Registrasi ) yang dikeluarkan oleh pemerintah sebagai penanggung jawab dalam pelayanan kesehatan masyarakat. STR adalah bukti tertulis sebagai pengakuan atas kompetensi profesi dari tenaga kesehatan sebelum tenaga kesehatan tersebut melakukan pelayanan kesehatan kepada masyarakat.

Dokter sebagai salah satu tenaga kesehatan bertanggung jawab untuk memberikan pelayanan kesehatan sesuai dengan peraturan perundangan yang berlaku yaitu Undang-undang Praktik Kedokteran dan Kode Etik Dokter.

Dokter yang melakukan praktik pelayanan kesehatan kepada masyarakat di rumah sakit terikat pada Kode Etik Dokter dan juga terikat pada Hospital By Laws sebagai ketentuan internal dari rumah sakit dimana dokter tersebut bertugas untuk memberikan pelayanan kesehatan kepada pasien ( masyarakat yang datang berobat ) yang kadangkala ketentuan internal tersebut menjadi kendala bagi dokter ybs dalam memberikan pelayanan kesehatan. Namun karena tujuan utama dari pemberian pelayanan kesehatan adalah untuk meningkatkan derajat kesehatan masyarakat maka perbedaan yang mungkin terjadi bisa diselesaikan secara internal.

\section{Saran}

Agar diperoleh pelayanan kesehatan yang baik maka seluruh tenaga kesehatan yang sudah memperoleh sertifikat kompetensi untuk melakukan registrasi kesehatan untuk mendapatkan STR.

Agar masyarakat dapat memperoleh pelayanan kesehatan yang baik maka masyarakat juga harus diedukasi tentang hak-haknya sebagai pasien melalui 
sosialisasi dari lembaga yang terkait.

Agar seluruh masyarakat mendapat kan haknya untuk memperoleh pelayanan kesehatan maka pemerintah harus menambah fasilitas kesehatan yang telah ada.

\section{Daftar Pustaka}

A.A Gde Maninjaya 2004, Manajemen Kesehatan, Edisi 2, EGC, Jakarta.

Bustami, 20011, Penjaminan Mutu Pelayanan Kesehatan, dan Akseptabilitasnya, Erlangga, Jakarta.

Cecep Tri Wibowo, 2014, Etika Hukum Kesehatan, Nusa Medika, Yogyakarta.

Gunawan Wijaya dan Ahmad Yani 2003, Hukum Tentang Perlindungan Konsumen, PT Gramedia Pustaka Utama, Jakarta

Guwandi J, 1991, Dokter dan Rumah Sakit, FKUI, Jakarta
Indra Bastian Suryono, 2011, Penyelesaian Sengketa Kesehatan, Salemba Medika, Jakarta

Soekidjo Noto Atmodjo, 2007, Promosi Kesehatan dan Ilmu Perilaku, Rineka Cipta,.Jakarta. Hukum Kesehatan, Rineka Cipta, Jakarta

Muninjaya, 2011, Manajemen Mutu Pelayanan Kesehatan, EGC, Jakarta

UU Nomor 29 Tahun 2004 tentang Praktek Kedokteran

UU Nomor 44 Tahun 2009 tentang Rumah Sakit.

UU Nomor 20 Tahun 2013 tentang Pendidikan Kedokteran

Permenkes Nomor 46 Tahun 2013 tentang Registrasi Tenaga Kesehatan.

Kepmenkes RI No.434/MEN.KES/X/1983 tentang berlakunya KODEKI (Kode Etik Kedokteran Indonesia)

Kode Etik Kedokteran Indonesia. 